\title{
KESEDIAAN DAN POTENSI MASYARAKAT DI MALAYSIA KE ARAH NEGARA RENDAH KARBON
}

(Readiness and Potential of Malaysian Society Towards Low Carbon Nation)

\author{
HUKIL SINO*, NUR ALYSSA AZAHARI, NORWAHIDA ZAMANI, AB AZIZ ISHAK, \\ MUHAMAD HILMI BABA, ATIAH AYUNNI ABDUL GHANI, MUHAMMAD \\ HASAMIZI MUSTAPA
}

\begin{abstract}
ABSTRAK
Malaysia telah berikrar untuk memberi komitmen dalam menangani perubahan iklim di peringkat global dengan menjadi negara rendah karbon pada tahun 2050. Masyarakat selaku pengguna utama karbon yang menyumbang kepada pelepasan karbon ke persekitaran melalui aktiviti seharian dilihat memainkan peranan yang amat penting untuk merealisasikan misi rendah karbon tersebut. Artikel ini ditulis untuk merungkai kesediaan dan potensi masyarakat di Malaysia merealisasikan matlamat negara rendah karbon. Pendekatan ulasan mendalam berasaskan pembacaan buku-buku ilmiah, jurnal tersohor dan rujukan atas talian dijadikan asas dalam merungkai dan menjawab persoalan tajuk yang dibincangkan. Dapatan menunjukkan bahawa masyarakat Malaysia mampu dan berpotensi untuk merealisasikan aspirasi pengurangan emisi karbon sebanyak 30\% menjelang tahun 2050 berdasarkan kepada kebersediaan masyarakat terhadap langkah-langkah mengurangkan emisi karbon yang didokong oleh Dasar-dasar kerajaan. Kesimpulannya masyarakat di Malaysia dipercayai memiliki kesediaan dan potensi untuk merealisasikan matlamat negara rendah karbon menjelang tahun 2050.
\end{abstract}

Kata kunci: Gas rumah hijau; Masyarakat rendah karbon; Perubahan iklim

\begin{abstract}
Malaysia has pledged to give a commitment to addressing climate change at a global level by aiming to become a low carbon nation by 2050. As primary carbon users who are accountable for carbon emission in the environment caused by their daily activities, society plays a crucial part in realizing the low carbon mission. This article was written to explore the readiness and potential of Malaysian society towards becoming a low carbon nation. The finding shows that Malaysians are capable and have the potential to fulfill the aspiration of low carbon emission as much as $30 \%$ by the year 2050 based on their readiness to adopt the mitigation measures advocated in the government policies. In conclusion, Malaysian society is believed to have the readiness and potential towards realizing low carbon nation goals by 2050.
\end{abstract}

Keywords: Green house gases; Low carbon society; Climate change

\section{PENGENALAN}

Malaysia ialah sebuah negara membangun yang memiliki persekitaran yang kondusif untuk aktiviti ekonomi dijalankan dengan pesat (Martin 2019). Kepesatan aktiviti ekonomi ini 
sekaligus telah meningkatkan kemakmuran negara serta menyumbang kepada peningkatan jumlah penduduk di Malaysia iaitu dianggarkan sebanyak 32.6 juta orang, berbanding 32.4 juta orang pada tahun lepas (Jabatan Perangkaan Malaysia 2019). Peningkatan kepadatan penduduk turut meningkatkan kepenggunaan karbon dalam aktiviti seharian sehingga berlakunya peningkatan pelepasan karbon ke atmosfera. Justeru Malaysia juga tidak terlepas daripada menghadapi isu pemanasan global disebabkan oleh perubahan iklim dunia. Malaysia telah mengalami peningkatan suhu sebanyak $0.18^{\circ} \mathrm{C}$ setiap dekad sejak dari tahun 1951 dan dianggarkan akan meningkat sebanyak $2^{\circ} \mathrm{C}$ menjelang tahun 2041-2050 disebabkan oleh ketidaktentuan cuaca (NAHRIM 2006).

Seperti yang diketahui umum, peningkatan karbon dan gas-gas rumah hijau yang lain dalam atmosfera mendorong kepada berlakunya fenomena pemanasan global yang amat mempengaruhi perubahan iklim dunia. Selain kehadiran gas-gas hijau daripada sumber luar berikutan sifatnya yang merentas sempadan, peningkatan gas rumah hijau di Malaysia juga berpunca daripada sumber tempatan. Kewujudan fenomena lautan Indian Ocean Dipole dan El Nino yang telah mengakibatkan keadaan cuaca kering dan kemarau di Sumatera dan Kalimantan turut mempengaruhi peningkatan suhu di negara ini. Kajian juga menunjukkan 98 peratus (Royer 2007) pemanasan global adalah berpunca daripada emisi karbon dioksida ke atmosfera akibat pembakaran bahan bakar fosil. Ini turut menjelaskan peranan $\mathrm{CO} 2$ dalam meningkatkan suhu dunia.

Masyarakat didefinisikan sebagai sekumpulan manusia yang sentiasa berinteraksi dan mempunyai kepentingan yang sama (Kamus Dewan Edisi Keempat 2005). Masyarakat ialah kumpulan manusia yang relatif mandiri, hidup bersama-sama dalam tempoh yang lama mendiami wilayah tertentu, mempunyai kebudayaan yang sama serta melakukan sebahagian besar kegiatan di dalam kelompoknya. Karbon pula didefinisikan sebagai sebatian kimia yang terdapat pada Jadual Berkala Unsur yang diwakilkan dengan simbol (C).

Masyarakat rendah karbon ialah masyarakat yang menggunakan tenaga karbon secara konsisten dengan kadar yang rendah untuk mengelakkan perubahan iklim. Menurut National Institute of Environmental Studies (2006), masyarakat rendah karbon ditakrifkan sebagai masyarakat yang berpartisipasi dalam sebarang usaha untuk menangani isu pencemaran alam sekitar. Komitmen masyarakat rendah karbon termasuklah mengambil tindakan yang sesuai dengan prinsip-prinsip pembangunan lestari sambil memastikan bahawa pembangunan tersebut memenuhi keperluan semua lapisan komponen masyarakat serta memberi sumbangan terhadap usaha global untuk menstabilkan kepekatan karbon dioksida (CO2) dan gas-gas rumah hijau bertujuan meminimumkan kesan perubahan iklim. Selain itu, masyarakat rendah karbon perlu menunjukkan sikap positif yang konsisten dalam menyokong penggunaan teknologi cekap tenaga atau sumber tenaga rendah karbon.

Masyarakat rendah karbon yang dimaksudkan di sini termasuk orang awam, golongan industri, organisasi bukan kerajaan dan kerajaan yang mempunyai kesedaran untuk mengubah tingkah laku mereka terhadap penggunaan tenaga. Masyarakat di Malaysia boleh memainkan peranan untuk merealisasikan matlamat rendah karbon dengan mengubah gaya hidup ke arah penggunaan tenaga alternatif yang boleh diperbaharui, atau mengurangkan kebergantungan terhadap bahan bakar fosil, atau membudayakan amalan 3R (mengurangkan, menggunakan semula dan mengitar semula) di dalam kehidupan seharian mereka.

Justeru artikel ini ditulis untuk meneroka kesediaan dan potensi masyarakat Malaysia ke arah mengurangkan emisi karbon serta mengenalpasti sistem sokongan di negara ini untuk merealisasikan matlamat negara rendah karbon. 


\section{PENGURANGAN EMISI KARBON DALAM RANCANGAN MALAYSIA}

Isu pemanasan global dan perubahan iklim adalah di antara isu dunia yang menarik perhatian masyarakat antarabangsa dan tempatan berikutan fenomena perubahan iklim yang semakin ekstrem dan telah mencetuskan pelbagai bencana alam seperti ribut taufan dan banjir di seluruh dunia. Jumlah emisi gas rumah hijau antropogenik dunia telah meningkat lebih pantas daripada tahun 2000 sehingga 2010 berbanding jumlah emisi tiga dekad sebelumnya (IPCC 2014). Emisi $\mathrm{CO}_{2}$ daripada pembakaran bahan api fosil dan industri menyumbang sebanyak 78 peratus kepada jumlah emisi gas rumah hijau dunia dari tahun 1970 sehingga 2010. Lebih 75 peratus peningkatan emisi gas rumah hijau dunia disumbangkan oleh sektor tenaga (47 peratus) dan industri (30 peratus) dan separuh daripada jumlah tersebut disumbang oleh negara membangun di mana aktiviti ekonomi dan pembinaan infrastruktur giat dijalankan (IPCC 2014).

Data Bank Dunia menunjukkan jumlah emisi $\mathrm{CO}_{2}$ di Malaysia pada tahun 2016 adalah sebanyak 248,289 kilotan iaitu kenaikan sebanyak 60,000 kilotan dari tahun 2006 (World Bank 2020) dan 200,000 kilotan dari tahun 1960. Ini menunjukkan bahawa emisi $\mathrm{CO}_{2}$ Malaysia telah meningkat dengan pesat sejajar dengan kadar pembangunan di negara ini serta menyumbang kepada emisi $\mathrm{CO}_{2}$ dunia.

Lima penyumbang terbesar pengeluaran gas rumah hijau di Malaysia adalah penjanaan kuasa elektrik (30.5\%), pengangkutan jalanraya (14.5\%), pelupusan sisa pepejal (10.8\%), emisi pengeluaran daripada operasi minyak dan gas (10.2\%) serta industri perkilangan dan pembinaan (8\%) (Zaid 2015). Malaysia telah memberikan komitmen untuk mengurangkan intensiti emisi $\mathrm{CO}_{2}$ Keluaran dalam Negara Kasar (KDNK) negara dalam Persidangan Perubahan Iklim Pertubuhan Bangsa-bangsa Bersatu di Copenhagen Denmark (COP15) yang berlangsung pada Disember 2009, dengan pengurangan sebanyak 40 peratus pada tahun 2020 berbanding tahun 2005. Selaras dengan komitmen tersebut, Malaysia telah memperkenalkan slogan bandar rendah karbon di beberapa kerajaan tempatan sebagai inisiatif ke arah pembentukan masyarakat rendah karbon. Slogan bandar rendah karbon telah diwujudkan untuk meningkatkan keterlibatan semua pemegang taruh dalam usaha mengurangkan emisi gas rumah hijau.

Sebelum persidangan tersebut, Malaysia telah membangunkan inisiatif 'hijau' dalam agenda pembangunan negara iaitu melalui Rancangan Malaysia ke-3 (RMK3), RMK 10, RMK 11 dan RMK 12 (Pejabat Perdana Menteri Malaysia 2020). Seawal RMK 3 (1976-1980), kerajaan telah mula memberi perhatian tentang kesan industri terhadap masyarakat dan alam sekitar. Walaupun masih meneruskan pelaksanaan Dasar Ekonomi Baru, impak negatif pembangunan ekonomi terhadap komponen sosial dan alam sekitar turut dipantau dan dikekang.

Inisiatif hijau dalam RMK 10 (2010-2015) diteruskan dengan memberi penumpuan kepada kepenggunaan tenaga. Melalui Dasar Baru Tenaga dalam Rancangan ini, perancangan strategik pembangunan bekalan tenaga telah dirancang dengan mempelbagaikan sumber tenaga termasuk penerokaan terhadap sumber tenaga boleh diperbaharui termasuklah tenaga nuklear sebagai tenaga alternatif. Selain itu, Dasar ini juga mensasarkan peningkatan pelaksanaan inisiatif kecekapan tenaga di sektor industri, komersil, kediaman dan pengangkutan. Secara ringkas Dasar ini akan dilaksanakan menggunakan pendekatan bersepadu supaya matlamat jaminan bekalan tenaga akan dapat dicapai.

RMK 11 (2016-2020) pula telah memberi penekanan kepada pertumbuhan, gaya hidup dan pembelajaran hijau mengikut konsep pembangunan mampan. Pertumbuhan hijau akan memastikan impak yang minimum terhadap alam sekitar serta pemuliharaan sumber asli secara optimum. Penentuan dasar, pengawalseliaan institusi, perkongsian tanggungjawab dan penilaian masyarakat ke atas alam sekitar akan ditingkatkan dalam Rancangan ini.

Gaya hidup hijau yang dicadangkan dalam Rancangan ini menumpukan kepada gaya hidup cekap tenaga. Inisiatif pengurangan penggunaan tenaga domestik dan industri akan 
dilaksanakan melalui amalan permintaan pengurusan tenaga. Perkhidmatan pengangkutan awam juga kan ditambahbaik untuk menggalakkan peralihan kepada kenderaan cekap tenaga. Selain itu, Rancangan ini juga mensasarkan peningkatan peratusan tenaga boleh baharu secara signifikan. Gaya hidup hijau yang disarankan turut merangkumi peningkatan aktiviti reduce, reuse dan recycle (3R). Rancangan ini turut mensasarkan penggunaan sisa sebagai sumber yang bernilai malah berpotensi dijadikan input untuk penukaran tenaga.

Matlamat pembangunan dan gaya hidup hijau yang disarankan dalam Rancangan ini akan dipupuk melalui pembelajaran hijau iaitu penerapan perkongsian tanggungjawab memelihara alam sekitar. Objektif pembelajaran hijau dalam Rancangan ini adalah meningkatkan kepenggunaan dan tingkahlaku beretika serta melahirkan minda mesra alam.

RMK12 (2021-2025) juga akan turut meneruskan inisiatif hijau dengan memberi penekanan kepada dimensi kemampanan alam sekitar yang merangkumi ekonomi biru (penggunaan laut secara mampan), teknologi hijau, tenaga boleh baharu serta adaptasi dan mitigasi perubahan iklim.

\section{PENGURANGAN EMISI KARBON DALAM DASAR DAN RANGKA KERJA DI MALAYSIA}

Malaysia juga mempunyai Dasar-Dasar yang mendokong usaha untuk mengurangkan pencemaran alam sekitar dan perubahan iklim iaitu Dasar Teknologi Hijau Negara dan Dasar Perubahan Iklim. Dasar Teknologi Hijau Negara telah dilancarkan oleh Datuk Seri Najib Razak, Perdana Menteri Malaysia ke-6 pada 24 Julai 2009 di antara lainnya mencari kaedah untuk mengurangkan penggunaan tenaga dan pada masa sama mempromosikan kecekapan guna tenaga serta memulihara dan meminimumkan kesan kepada alam sekitar. Dasar ini juga turut memberi tumpuan kepada peningkatan kesedaran dan penggunaan orang awam terhadap teknologi hijau.

Dasar Perubahan Iklim Negara (12 Julai 2009) pula secara khusus berperanan sebagai satu rangka kerja untuk menggerak dan memberikan panduan kepada agensi kerajaan, industri, komuniti dan pihak berkepentingan dalam menghadapi cabaran perubahan iklim secara menyeluruh dan bersepadu. Dasar ini menitikberatkan pengukuhan keupayaan negara agar impak perubahan iklim dapat dikurangkan di samping menggalakkan langkah mitigasi yang boleh mempertingkatkan pembangunan secara lestari (Pejabat Perdana Menteri Malaysia 2020).

Malaysia di peringkat antarabangsa juga komited mengurangkan emisi gas rumah hijau dan perubahan iklim dalam beberapa protokol antarabangsa termasuk protokol Montreal (1987) dan Kyoto (1997) serta persidangan iklim Copenhagen (2009) dan Paris (2015). Sewaktu persidangan Copenhagen, Malaysia telah memberikan komitmen untuk mengurangkan 40 peratus intensiti pelepasan gas rumah hijau berbanding Keluaran Dalam Negara Kasar menjelang 2020 manakala dalam persidangan di Paris, sasaran tersebut telah ditingkatkan kepada 45 peratus menjelang 2030 bergantung kepada bantuan yang dihulur negara maju seperti negara Jepun dan United Kingdom melalui jaringan kerjasama. Sehingga tahun 2014, Malaysia telah berjaya mengurangkan emisi gas rumah hijau sehingga 33 peratus (Bernama 2019).

Pada tahun 2011, Kementerian Tenaga, Teknologi Hijau dan Air memperkenalkan Sistem Berasaskan Prestasi yang dikenali sebagai Rangka Kerja Bandaraya Rendah Karbon (LCCF) sebagai panduan kepada pihak berkuasa tempatan dan pemaju dalam membuat keputusan berhubung penyelesaian persekitaran yang lebih hijau. Peningkatan rakan kongsi yang berminat dalam LCCF menandakan keberhasilan usaha ini. Pada tahun 2012, sebanyak sembilan pihak berkuasa tempatan iaitu termasuklah Dewan Bandaraya Shah Alam, Majlis 
Perbandaran Subang Jaya, Dewan Bandaraya Kuala Lumpur, Majlis Perbandaran Sepang dan lain-lain telah menjadi rakan kerjasama untuk LCCF (Malaysia Green Technology Cooperation, 2019). Peningkatan jumlah pihak berkuasa tempatan yang menggunapakai rangka kerja ini telah mendorong kepada peningkatan permintaan terhadap pasaran penyelesaian alternatif atau penyelesaian hijau di Malaysia yang membantu terus merangsang ekonomi hijau tempatan dan mempercepat transformasi ke bandar rendah karbon.

Salah satu perintis perbandaran hijau yang utama ialah Pusat Pentadbiran Kerajaan Persekutuan Putrajaya. Ia menjadi peneraju kepada bandar rendah berkarbon yang lestari, dengan matlamat mengurangkan emisi pelepasan gas rumah hijau sebanyak 60 peratus menjelang 2025 berbanding tahap emisi pada 2012, dan mengurangkan haba dalam bandar sebanyak dua darjah celsius. Kebanyakan bangunan kerajaan di Putrajaya telah menerima pakai piawaian bangunan hijau dan dinilai oleh Indeks Bangunan Hijau. Inisiatif lain yang dilaksanakan termasuk pemasangan panel solar di bangunan kerajaan terpilih, penggunaan lampu LED secara meluas, pengaktifan bas elektrik, perluasan laluan basikal, penempatan mesin pengkomposan, dan pengenalan kepada pertanian bandar. (Perbadanan Putrajaya 2019)

Salah satu pihak berkuasa tempatan yang aktif melaksanakan program rendah karbon ialah Dewan Bandaraya Kuala Lumpur (DBKL). Program rendah karbon yang dilaksanakan oleh DBKL termasuk menukarkan semua lampu jalan kepada lampu LED, memasang peralatan cekap tenaga di semua bangunan DBKL, menyediakan parkir khas kepada kenderaan cekap tenaga (EEV), menanam lebih banyak pokok, serta menggalakkan orang ramai untuk berjalan dan berbasikal di bandar. Usaha DBKL untuk mencapai sasaran dan strategi yang terkandung di bawah Pelan Induk Masyarakat Rendah Karbon Kuala Lumpur 2030 ini turut dibantu dari segi kepakaran dan koordinasi teknikal oleh Institut Strategi Alam Sekitar Global (IGES) dan Pihak Berkuasa Pembangunan Tenaga Lestari (SEDA), Universiti Teknologi Malaysia (UTM). DBKL juga turut berkolaborasi dengan Kerajaan Metropolitan Tokyo (TMG) yang telah menunjukkan prestasi yang amat membanggakan penurunan emisi gas rumah hijau.

Majlis Perbandaran Seberang Perai telah menerima suntikan dana daripada kerajaan untuk menaiktaraf sektor tenaga di kawasan tersebut membolehkan pemasangan solar panel yang mampu menjana tenaga elektrik bersih sebanyak kira-kira 6,130kWh sebulan dan mengurangkan emisi karbon sebanyak $77.30 \mathrm{tCO}_{2}$ dalam tempoh 2 tahun (2015-2017) (Malaysia Green Technology Cooperation 2019). Majlis Bandaraya Shah Alam juga telah berjaya mengurangkan secara signifikan emisi karbon iaitu sebanyak 3,468 $\mathrm{tCO}_{2}$ melalui langkah-langkah pengurusan efektif air, tenaga, sisa dan pengangkutan. Majlis Perbandaran Kelang juga telah menunjukkan hasil yang memberangsangkan dengan pengurangan sebanyak $720.45 \mathrm{tCO}_{2}$ melalui pengurusan tenaga dan sisa serta pemuliharaan alam semulajadi dalam tempoh yang sama.

Selain pihak berkuasa tempatan, kerajaan juga memperuntukkan sebahagian dana kepada pengeluar kenderaan cekap tenaga atau EEV untuk meningkatkan pengeluaran melalui pertukaran kepakaran serta teknologi dengan negara maju. Malaysia berhasrat untuk menjadi antara hab pengeluar Electrical Engine Vehicle (EEV). Malaysia mempunyai sebanyak 5,403 kenderaan elektrik (EV) berdaftar yang digunakan di atas jalanraya. Kenderaan Plug-in Hybrid (PHEV), sebanyak 46,981 unit kenderaan berdaftar yang digunakan di jalanraya awam sehingga 31 Mac 2019. Selangor mencatatkan jumlah kenderaan EV berdaftar dengan 2,791 unit sementara Wilayah Persekutuan mempunyai jumlah kenderaan hibrid tertinggi pada 25,360 unit (Malay Mail 2019). Kerajaan turut memberikan pelbagai insentif untuk menggalakan pembelian kenderaan dengan teknologi mesra alam, antaranya ialah pengurangan 50 peratus untuk cukai jalan bagi kenderaan EV dan PHEV. Model popular EV di Malaysia di antaranya ialah Nissan Leaf, Renault Zoe, Renault Twizy dan Tesla. Model PHEV yang popular pula ialah seperti Volvo XC90, BMW X5 dan BMW 3-Series. 


\section{PEMEGANG TARUH RENDAH KARBON SELAIN KERAJAAN DI MALAYSIA}

Usaha untuk mengurangkan emisi gas rumah hijau dan melahirkan masyarakat rendah karbon adalah usaha yang perlu dijalankan secara kolektif dengan melibatkan pelbagai pemegang taruh termasuk kerajaan, industri, NGO dan komuniti. Pihak kerajaan perlu bertindak sebagai agen pencetus dan penggalak dan disokong oleh pemegang taruh yang lain (Shea and Nishioka 2008).

Industri memainkan peranan yang amat penting dalam usaha mengurangkan emisi karbon di negara ini kerana sektor ini menggunakan tenaga dalam skala yang besar. Kajian yang telah dijalankan di Kulim Hi-Tech Park Kedah menunjukkan bahawa kebanyakan industri membuat pelaburan ke atas kecekapan tenaga, kitar semula dan guna semula bahan, teknologi mesra alam, latihan dalaman ekonomi hijau serta pembelian bahan-bahan yang kurang menjejaskan alam sekitar (Husin Abdullah et al 2017). Pelaburan ini telah didorong oleh keprihatinan industri terhadap kesan operasi dan produk mereka kepada alam sekitar. Dapatan kajian ini menunjukkan bahawa sebahagian sektor industri di negara ini sememangnya terlibat dalam pelaksanaan ekonomi hijau dan ini amat bermakna kepada usaha mengurangkan emisi gas rumah hijau termasuk $\mathrm{CO}_{2}$.

Selain kerajaan, Malaysia juga mempunyai gabungan pertubuhan bukan kerajaan (NGO) yang memainkan peranan dalam usaha mengurangkan emisi gas rumah hijau iaitu Pertubuhan Perubahan Iklim Malaysia (The Malaysian Climate Change Group, MCGG) (CETDEM 2004). MCGG telah ditubuhkan pada 16 Disember 1992 dan terdiri daripada Persatuan Perlindungan Alam Sekitar Malaysia (Environmental Protection Society Malaysia, EPSM), Pusat Alam Sekitar, Teknologi dan Pembangunan Malaysia (Centre for Environment, Technology and Development, Malaysia, CETDEM) dan Persatuan Alam Sekitar Malaysia (Malaysian Nature Society, MNS). Persatuan Pengguna Perak (Perak Consumers' Association, PCA) telah menyertai pertubuhan ini pada Ogos 2002.

MCGG telah ditubuhkan semasa Bengkel Penyelidikan dan Pemantauan CANSEA (Conservation Agriculture in South-East Asia) di Kuala Lumpur. Pendekatan pemindahan teknologi dalam pertanian telah diadaptasi oleh MCGG untuk turut mengurangkan emisi gas rumah hijau di Malaysia. MCGG telah menggariskan keutamaan dalam pemindahan teknologi dengan mencadangkan beberapa teknologi mesra alam termasuk tenaga angin, solar dan hidro; biogas dan biojisim; serta sel fuel dan penetapan karbon kekal (permanent carbon fixation). Selain itu, MCGG juga mencadangkan penggunaan peralatan, kenderaan dan kediaman cekap tenaga serta pengurangan sisa.

Orang awam di Malaysia juga dipercayai berpotensi untuk terlibat dalam usaha mengurangkan emisi karbon kerana dilihat semakin mengambil berat tentang isu-isu berkaitan perubahan iklim melalui peningkatan perkongsian maklumat dan pengetahuan tentang alam sekitar serta galakan supaya turut serta dalam menangani isu alam sekitar. Pengetahuan dan kesedaran tentang alam sekitar dan pembangunan telah diterapkan sejak di bangku sekolah melalui Pendidikan Pembangunan Lestari atau Education for Sustainable Development (ESD) yang meliputi tiga tunggak utama iaitu sosial, ekonomi dan alam sekitar. Di Malaysia, ESD telah dilaksanakan secara formal dan tidak formal menerusi pelbagai program seperti Program Sekolah Lestari Anugerah Alam Sekitar (SLAAS) pada tahun 2005 (WCED 2003). Pendidikan alam sekitar dan pembangunan lestari juga turut diteruskan di peringkat pengajian tinggi. Selain medium pendidikan formal, pendidikan tidak formal juga aktif dijalankan oleh pelbagai pihak termasuk NGO dan sektor perniagaan.

Ketidakcekapan penggunaan tenaga dan kebergantungan terhadap bahan api fosil sebagai sumber tenaga telah dikenalpasti sebagai faktor yang menyumbang kepada pembebasan gas rumah hijau di negara ini (Ahmad Suhael 2019). Justeru terdapat langkah praktikal yang boleh diambil oleh orang awam selaku pengguna tenaga terbesar, untuk mengurangkan emisi gas rumah hijau termasuk karbon serta menggunakan tenaga boleh diperbaharui iaitu tenaga solar, 
hidro dan angin dan biomas untuk aktiviti domestik; mengurangkan penggunaan elektrik dan mempromosi penggunaan peralatan jimat tenaga bagi bangunan kediaman dan komersil; menggunakan pengangkutan lestari termasuk pengangkutan tidak bermotor (berjalan kaki dan berbasikal) dan pengangkutan awam serta menggalakkan penggunaan dan pengeluaran kenderaan cekap tenaga EEV seperti kereta hibrid; serta mengamalkan kepenggunaan berhemah serta melaksanakan konsep 3R dalam pengurusan sisa (mengurangkan, mengguna semula, dan mengitar semula). Selain itu, orang awam juga boleh memainkan peranan melalui pendekatan pendidikan tidak formal seperti menyebarkan maklumat dan pengetahuan mengenai kesan perubahan iklim, langkah yang perlu diambil untuk mengurangkan risiko bencana dan promosi aktiviti seharian yang boleh mengurangkan emisi karbon.

\section{PROSPEK MASYARAKAT RENDAH KARBON DI MALAYSIA}

Dapatan yang diperolehi dalam kajian ini menunjukkan bahawa masyarakat Malaysia yang terdiri daripada pihak kerajaan, industri, pertubuhan bukan kerajaan dan orang awam menunjukkan kesediaan dan potensi untuk merealisasikan matlamat negara rendah karbon menjelang tahun 2050. Kerajaan Malaysia telah membangunkan kerangka dan persekitaran yang sangat kondusif untuk semua pemegang taruh memainkan peranan dalam usaha mengurangkan emisi karbon negara. Bantuan dan bimbingan kerajaan kepada sektor industri untuk memperkasa ekonomi hijau telah membantu sektor ini untuk menjalankan operasi dan berkembang secara mesra alam sekaligus mengurangkan emisi karbon. Hubungan dan reputasi baik Malaysia di peringkat antarabangsa pula membolehkan pertubuhan bukan kerajaan negara ini mewujudkan jaringan dengan pelbagai organisasi antarabangsa untuk berkongsi maklumat dan mekanisme rendah karbon dari negara lain. Kemajuan dan kemakmuran negara ini juga memberikan akses kepada orang awam kepada maklumat berkaitan dengan perubahan iklim, emisi gas rumah hijau, inisiatif mesra alam dalam kehidupan seharian termasuk langkahlangkah ke arah rendah karbon di negara ini.

Sistem sokongan yang kukuh di negara ini dalam konteks menangani perubahan iklim dan emisi gas rumah hijau dijangka amat membantu masyarakat di Malaysia untuk melaksanakan komitmen rendah karbon dalam kehidupan seharian. Walau bagaimanapun, jangkaan ini adalah berasaskan kepada data sekunder yang diperolehi daripada analisa yang telah dijalankan ke atas dokumen yang berkaitan. Justeru, jangkaan ini perlu dibuktikan melalui kajian lapangan untuk memperolehi data primer yang menunjukkan dapatan kajian dan rumusan yang sebenar.

\section{KESIMPULAN}

Kajian ini merumuskan bahawa masyarakat Malaysia bersedia dan berpotensi untuk memainkan peranan dalam usaha ke arah negara rendah karbon menjelang tahun 2050. Kajian ini juga merumuskan bahawa sistem sokongan sedia ada di Malaysia adalah mantap untuk merealisasikan matlamat negara rendah karbon tersebut. Walau bagaimanapun, Malaysia juga perlu mengukuhkan hubungan diplomatik dengan negara luar dan mempertingkatkan kerjasama supaya pertukaran teknologi dan maklumat dapat dilaksanakan secara berterusan. Kajian ini mencadangkan agar kajian lapangan dijalankan untuk mengenalpasti tahap kesediaan dan potensi masyarakat rendah karbon di Malaysia untuk mendapatkan input sebenar bagi membolehkan usaha dijalankan untuk meningkatkan tahap dan potensi tersebut. 


\section{RUJUKAN}

Ahmad Suhael Adnan. 2019. Malaysia Berjaya Kurangkan 33 Peratus Gas Rumah Hijau. Berita Harian. https://www.bharian.com.my/berita/nasional/2019/04/553724/malaysia-berjayakurangkan-33-peratus-gas-rumah-hijau (Akses 20 Mac 2020).

Bernama. 2019. KL dan Tokyo Bekerjasama Capai Sasaran Masyarakat Rendah Karbon. http://www.bernama.com/bm/news.php?id=1760034 (Akses 25 Mac 2020).

Brian, M. 2019. Turbocharging Malaysia's Prosperity. The Star. https://www.thestar.com.my/opinion/columnists/on-yourside/2019/12/27/turbocharging-malaysias-prosperity (Akses 18 Jun 2020).

CETDEM. 2004. Malaysian Climate Change Group (MCCG). http://www.cetdem.org.my/climate_change/mccg.html.

https://www.mcmc.gov.my/skmmgovmy/media/General/pdf/Sesi-6-Mewujudkan-bandarpintar-untuk-kelangsungan-hidup-rakyat.pdf.

Hussin Abdullah, Nor'Aznin Abu Bakar, Mohd Razani Mohd Jali, \& Fatimah Wati Ibrahim. 2017. The Current State of Malaysia's Journey towards a Green Economy: The Perceptions of the Companies on Environmental Efficiency and Sustainability. International Journal of Energy Economics and Policy, 7(1): 253-258.

IPCC. 2014. Fifth Assessment Report Synthesis Report: Climate Change 2014. WHO \& UNEP. https://www.ipcc.ch/report/ar5/syr/.

Jim, S., and S. Nishioka. 2008. Policies and Practices for A Low-Carbon Society. Climate Policy. 8(sup1): S5-S16.

Kamus Dewan Bahasa Keempat. 2005. https://prpm.dbp.gov.my/cari1 ?keyword=rata-riti

Malay Mail. 2019. 50\% Road Tax Reduction for Electrics and Hybrids. https://www.malaymail.com/news/malaysia/2019/04/22/50pc-road-tax-reduction-forelectric-hybrid-cars/1745823?utm_source=FBdlvr\&utm_medium=facebook (Akses 14 Februari 2020).

Malaysia Green Technology and Climate Change Malaysia. 2019. Low Carbon Cities. https://www.greentechmalaysia.my/our-services/low-carbon-cities-framework/.

National Institute of Environmental Studies. 2006. COP12 \& COP/MOP2 Side Event: Global Challenges Toward a Low-Carbon Society (LCS) Through Sustainable Development (SD). Japan: Tokyo. https://www.nies.go.jp/whatsnew/2006/20061026/20061026e.html

Pejabat Perdana Menteri Malaysia. 2020. https://www.pmo.gov.my/ms/rancangan-malaysia/

Perbadanan Putrajaya. 2019. Putrajaya Bandar Hijau Karbon Rendah.

United Nations. 1987. Montreal Protocol. Canada: Montreal.

United Nations. 1997. Kyoto Protocol. Japan: Kyoto.

United Nations. 2009. The United Nations Climate Change Conference. Copenhagen, Denmark.

United Nations. 2016. United Nations Framework Convention on Climate Change. Paris, France.

World Bank. 2020. $\mathrm{CO}_{2}$ emissions (metric tonnes per capita) - Malaysia. https://data.worldbank.org/indicator/EN.ATM.CO2E.PC?locations=MY.

World Commission on Environment and Development (WCED). 2003. Report of the World Commission on Environment and Development: Our Common Future.

\section{HUKIL SINO}

Fakulti Sains Kesihatan, Kampus Kuala lumpur

Jalan Raja Muda Abdul Aziz, 50300, Kuala Lumpur 
NUR ALYSSA AZAHARI,

Fakulti Sains Kesihatan, Kampus Kuala lumpur

Jalan Raja Muda Abdul Aziz, 50300, Kuala Lumpur

NORWAHIDA ZAMANI

Fakulti Sains Kesihatan, Kampus Kuala lumpur

Jalan Raja Muda Abdul Aziz, 50300, Kuala Lumpur

AB AZIZ ISHAK

Fakulti Sains Kesihatan, Kampus Kuala lumpur

Jalan Raja Muda Abdul Aziz, 50300, Kuala Lumpur

MUHAMAD HILMI BABA

Fakulti Sains Kesihatan, Kampus Kuala lumpur

Jalan Raja Muda Abdul Aziz, 50300, Kuala Lumpur

ATIAH AYUNNI ABDUL GHANI

Fakulti Sains Kesihatan, Kampus Kuala lumpur

Jalan Raja Muda Abdul Aziz, 50300, Kuala Lumpur

MUHAMMAD HASAMIZI MUSTAPA

Fakulti Sains Kesihatan, Kampus Kuala lumpur

Jalan Raja Muda Abdul Aziz, 50300, Kuala Lumpur

*Pengarang untuk surat menyurat: hukilsino@ukm.edu.my 